\title{
多数機フォーメーションフライトのための \\ 連続推力推進による燃料最小誘導則*1 \\ Fuel-Optimal Continuous-Thrust Guidance Algorithms for a Large Number of Formation Flying Spacecraft
}

\author{
河 原 吉 伸*2 津 田 雄 *3 $^{* 3}$ 中須賀 真 - *2 \\ Yoshinobu KaWAhara, Yuichi Tsuda and Shinichi NAKasuka
}

Key Words : Fuel-Optimal Guidance, Continuous-Thrust, Formation Flight

\begin{abstract}
A continuous-thrust guidance algorithm suitable for a formation flying of a large number of spacecraft having electric propulsion systems are discussed. This algorithm generates continuous-thrust transfer trajectory between any two arbitrary states, which can be optimized in term of total fuel consumption for a formation changing. The algorithms are effective not only in term of fuel consumption but also in term of information quantity to be shared among member spacecraft. Moreover taking computational simplicity into consideration, a quasi-optimal continuous-thrust guidance algorithm are derived.
\end{abstract}

\section{本稿で使用する 記号}

\section{座標系}

$\Sigma_{i}$ : 中心天体を原点に持つ慣性座標系

$\Sigma_{r}$ : 参照軌道系に原点を持つ回転座標系

$\Sigma_{c}:$ フォーメーション中心座標系

変数, 定数

$t:$ 時間

$\theta$ : true anomaly

$\boldsymbol{r}_{i}$ : 座標系 $\Sigma_{i}$ における位置 $\left(=\left[x_{i}, y_{i}, z_{i}\right]\right)$

$\boldsymbol{r}_{r}$ : 座標系 $\Sigma_{r}$ における位置 $\left(=\left[x_{r}, y_{r}, z_{r}\right]\right)$

$\boldsymbol{r}$ : 式 (3)により変換された位置

$\boldsymbol{y}$ : 式 (5)により定義される状態量

$\boldsymbol{\xi}$ ：式 (20) により定義される状態量

$\boldsymbol{u}$ : 式 (10)により定義される制御入力

$\boldsymbol{\Phi}$ ：推移行列 . ただし, $\boldsymbol{\Phi}^{-1}=\left[\boldsymbol{G}_{6 \times 3}, \boldsymbol{H}_{6 \times 3}\right]$

$\boldsymbol{l}:$ 随伴行列. ただし, $\boldsymbol{l}^{\mathrm{T}}=\left[\boldsymbol{p}^{\mathrm{T}}, \boldsymbol{q}^{\mathrm{T}}\right]$

$\boldsymbol{P}$ : primer vector (式 (18))

$\lambda$ : 任意の 6 次元定ベクトル

$\nu$ : 終端拘束条件に関する随伴変数

$\boldsymbol{A}$ : 線形運動方程式のシステム行列 (式 (6))

$\beta$ : 線形運動方程式の入力係数 (式 (7))

$s:($ 式 $(8)$ )

$\boldsymbol{w}$ : 線形運動方程式の制御ベクトル(式 $(9))$

$T:$ 推力ベクトル

\footnotetext{
*1 (C) 2004 日本航空宇宙学会

平成 15 年 7 月 31 日原稿受理

*2 東京大学大学院工学系研究科航空宇宙工学専攻

*3 宇宙航空研究開発機構 (JAXA) 宇宙科学研究本部
}

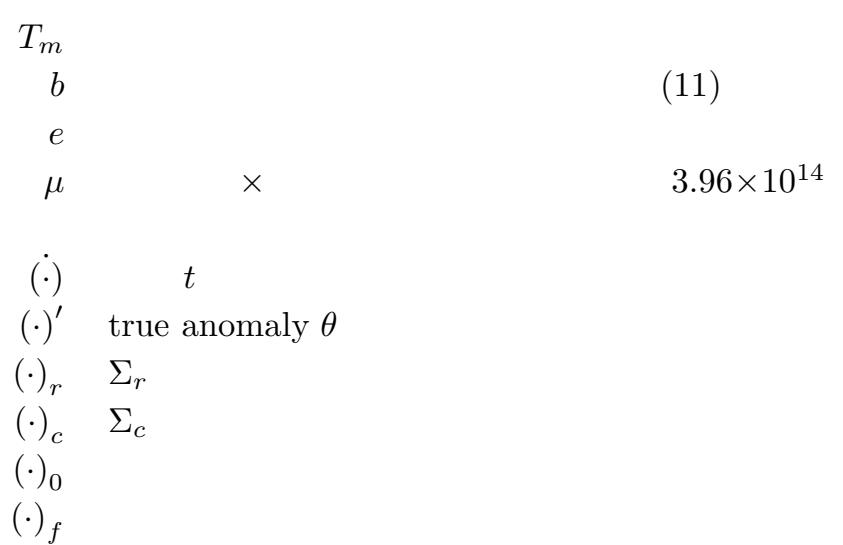

1.は じめ に

フォーメーションフライトは今後の深宇宙や地球軌道ミッ ションにとって非常に重要な技術の一つである.多数機の フォーメーションは冗長性・再構成能力・即応性を持った システムを構筑でき，また多点同時観測を可能にしたり， 大規模構造物の代替としても有望である .さらには各衛星 が別々の機能を持ち, フォーメーション全体として一つの システムとして機能する , "Virtual Orbital Platform"1) などのアイデアも提案されている .こういったミッション を行う際にも，将来的にはフォーメーションを構成する衛 星数は 100 機オーダーの多数機になる場合もあり, フォー メーション中の各衛星は自律分散的な誘導を行うことが予 想される.このような多数機のフォーメーションを実現す る際には, 各衛星の相対位置を適切に維持 (隊形維持) し たり, 別のものに変更 (隊形変更) したりするための軌道 制御 (フォーメーションフライト技術) が必須である.こ の際, 誘導時のフォーメーション全体で共有する情報量や 
計算コストをできるだけ小さくすることは，光のような多 数機フォーメーションの実現を左右する要素であることは 容易に想像がつく .

本稿では, このような理由から隊形変更時の情報量・計 算量を考慮した , 多数機のフォーメーションフライトに適 した燃料最小連続推力誘導則について論じる。“連続推力” とは , 例えば電気推進を軌道変更に利用する場合にあたる . まず少ない情報量を用いた任意の 2 点間の燃料最小連続推 力軌道を求め, 次にフォーメーション全体の大域的な燃料 最小誘導則について述べる .さらにこの方法で問題となる 計算時間を克服するため, フォーメーション位置を決める 際にインパルス近似を用いる方法を提案する .

\section{2. 参照軌道周りの線形運動方程式と推移行列 ${ }^{2)}$}

2.1 座標系の定義 フォーメーションフライトでは各衛 星同士は近傍を飛行するので, フォーメーション重心運動 を表す参照軌道周りに線形化された回転座標系を考えれば よい，本稿では，参照軌道としてどんな円錐軌道でも扱え るようにする (円軌道については後の解析解を利用する) .

第 1 図に示すように，中心天体を原点にした慣性座標系 を $\Sigma_{i}$ ，光して参照軌道上に原点を持つ回転座標系を $\Sigma_{r}$ と し， $\Sigma_{r}$ の $x$ 軸を中心天体から衛星の向き, $y$ 軸を衛星の 進行方向，光して $z$ 軸を兴れらと右手系を成すようにとる。

2.2 運動方程式 ${ }^{2,3)}$ まず中心天体周りの軌道の運動方 程式は次式で与えられる .

$$
\ddot{\boldsymbol{R}}(t)=-\frac{\mu}{R(t)^{3}} \boldsymbol{R}(t)+\boldsymbol{f}
$$

これを参照軌道周りに線形化する際に，独立变数を $t$ (時 間) から $\theta$ (true anomaly) へと変換し (式 (2)を用いる)， さらに式 $(3)$ の変換を施すと，見通しのよい式が得られる .

$$
\begin{aligned}
& \dot{(\cdot)}=(\cdot)^{\prime} \dot{\theta} ; \quad(\cdot)=(\cdot)^{\prime \prime} \dot{\theta}^{2}+\dot{\theta} \dot{\theta}^{\prime}(\cdot)^{\prime} \\
& \boldsymbol{r}(\theta)=(1+e \cos \theta) \boldsymbol{r}_{r}(\theta)
\end{aligned}
$$

これらを利用して次の線形化された運動方程式をえる．

$$
\boldsymbol{y}^{\prime}(\theta)=\boldsymbol{A}(\theta) \boldsymbol{y}(\theta)+\beta(\theta) \boldsymbol{w}(\theta)
$$

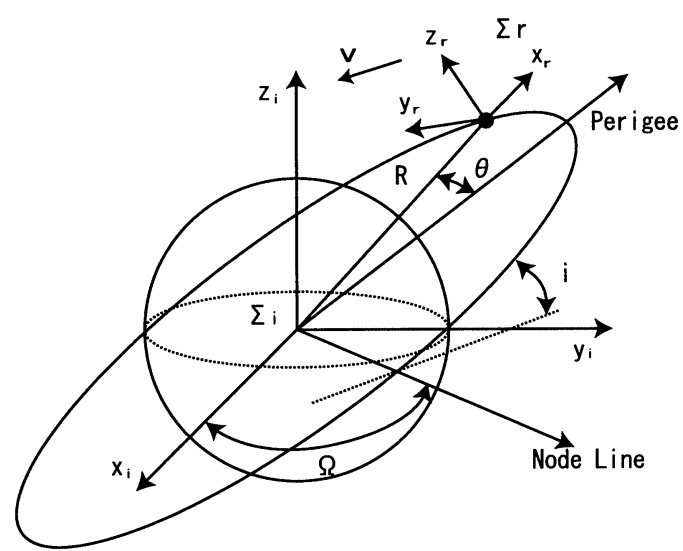

第1図 座標系の定義
ここで

$$
\begin{aligned}
& \boldsymbol{y}(\theta)=\left[\begin{array}{c}
\boldsymbol{r}(\theta) \\
\boldsymbol{r}^{\prime}(\theta)
\end{array}\right] \\
& \boldsymbol{A}(\theta)=\left[\begin{array}{cccccc}
0 & 0 & 0 & 1 & 0 & 0 \\
0 & 0 & 0 & 0 & 1 & 0 \\
0 & 0 & 0 & 0 & 0 & 1 \\
3 / s(\theta) & 0 & 0 & 0 & 2 & 0 \\
0 & 0 & 0 & -2 & 0 & 0 \\
0 & 0 & -1 & 0 & 0 & 0
\end{array}\right] \\
& \beta(\theta)=b / s(\theta)^{3} \\
& s(\theta)=1+e \cos \theta \\
& \boldsymbol{w}(\theta)=\left[\begin{array}{l}
\mathbf{0}_{3 \times 1} \\
\boldsymbol{u}(\theta)
\end{array}\right] \\
& \boldsymbol{u}(\theta)=\frac{\boldsymbol{T}(\theta)}{T_{m}}
\end{aligned}
$$

$b$ は最大推力 $\left(T_{m}\right)$ と衛星質量 $(m)$ に比例する量で次式で 表される。

$$
b=\frac{L^{6} T_{m}}{\mu^{4} m}
$$

$L$ は衛星の中心天体周りの角運動量 (定数) , $\mu$ は (重力 定数 $\times$ 中心天体の質量) である.ここでの導式では，推進 による衛星質量の変化は初期衛星質量に比べ十分小さいと 仮定している。

2.3 推移行列 ${ }^{4)}$ 線形運動方程式 (4) には推移行列 $(\boldsymbol{\Phi})$ の解析解が存在し，y は次式のように表せる .

$$
\boldsymbol{y}(\theta)=\boldsymbol{\Phi}(\theta)\left[\boldsymbol{\Phi}\left(\theta_{0}\right)^{-1} \boldsymbol{y}_{0}+\int_{\theta_{0}}^{\theta} \beta(\tau) \boldsymbol{H}(\tau) \boldsymbol{u}(\tau) \mathrm{d} \tau\right]
$$

$\boldsymbol{H}(\theta)$ は推移行列の逆行列の右半分からなる行列，つまり $\boldsymbol{\Phi}^{-1}=\left[\boldsymbol{G}_{6 \times 3}, \boldsymbol{H}_{6 \times 3}\right]$ である. $\boldsymbol{\Phi}$ の解析解が求まることは 重要で, 光れにより推移軌道における状態量は積分計算な して即座に求まる。

\section{3. 低推力推進による燃料最小誘導3 5)}

低推力推進は，推進器の制約によって二つに分類される . 一つは推進器がスラストの大きさを自由に変化させられな い場合 (CEV; constant ejection velocity) であり，もう 一つは推進器か限られた動力内でスラストの大きさを自由 に変化させられる場合 (LP; limited power) である6)

本研究では，LPに関する燃料最小誘導について考える。

3.1 燃料最小化問題とその評価関数 ここで考える誘 導の目的は，任意の初期条件から指定時刻に指定した運動 状態

$$
\boldsymbol{y}\left(\theta_{0}\right)=\left[\begin{array}{c}
\boldsymbol{r}\left(\theta_{0}\right) \\
\boldsymbol{r}^{\prime}\left(\theta_{0}\right)
\end{array}\right], \quad \boldsymbol{y}\left(\theta_{f}\right)=\left[\begin{array}{c}
\boldsymbol{r}\left(\theta_{f}\right) \\
\boldsymbol{r}^{\prime}\left(\theta_{f}\right)
\end{array}\right]
$$


を最小燃料により実現することである．つまり，衛星質量 の時間変化 $\dot{m}(t)$ の積分值を最小化する .

衛星質量の時間変化は, 推進器の電力などの動力 $P(t)$ を用いて次のように表せる .

$$
\dot{m}(t)=-\frac{|\boldsymbol{T}(t)|^{2}}{2 P(t)}
$$

上式からも分かるように, 質量変化を最小にするには少 なくとも $P$ は最大であることが分かる. 従って, 弚の最大 推力を $P_{\max }$ として，また独立変数を $\theta$ に変換して式 $(14)$ を整理すると

$$
m^{\prime}(\theta)=-\frac{L^{3}}{2 P_{\max } \mu^{2}} \frac{|\boldsymbol{T}(\theta)|^{2}}{s(\theta)^{2}}
$$

となる ${ }^{6}$.ここで式 (10) で定義した制御入力 $\boldsymbol{u}$ を用いれ ば, 評価関数として次式を得る.

$$
J(\boldsymbol{u}(\theta))=\int_{\theta_{0}}^{\theta_{f}} \frac{\boldsymbol{u}(\tau)^{\mathrm{T}} \boldsymbol{u}(\tau)}{s(\tau)^{2}} \mathrm{~d} \tau
$$

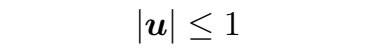

以上より，低推力推進による燃料最小誘導問題は微分方 程式 (4) を満たしつつ, 評価関数 (16) を最小にする制御入 力 $\boldsymbol{u}(\theta)(\leq 1)$ を求めることに帰着される. 兴のときの境 界条件は, 式 (13)で与えられる。

3.2 燃料最小誘導則 運動方程式 (4)の状態量に対する 随伴変数を $l(\theta)$ とするとハミルトニアンは次のように求 められる .

$$
\begin{aligned}
H= & \boldsymbol{l}(\theta)^{\mathrm{T}} \boldsymbol{A}(\theta) \boldsymbol{y}(\theta) \\
& +\frac{1}{2 s(\theta)^{2}}\left[\boldsymbol{u}(\theta)^{\mathrm{T}} \boldsymbol{u}(\theta)\right. \\
& \left.+2 s(\theta)^{2} \beta(\theta) \boldsymbol{q}(\theta)^{\mathrm{T}} \boldsymbol{u}(\theta)\right]
\end{aligned}
$$

ここに $\boldsymbol{q}$ は随伴変数ベクトルの下半分, つまり $\boldsymbol{l}(\theta)^{\mathrm{T}}=$ $\left[\boldsymbol{p}(\theta)^{\mathrm{T}}, \boldsymbol{q}(\theta)^{\mathrm{T}}\right]$ である .

次のようなべクトルを定義する .

$$
\begin{aligned}
\boldsymbol{P}(\theta) & =s(\theta)^{2} \beta(\theta) \boldsymbol{q}(\theta) \\
& =s(\theta)^{2} \beta(\theta) \boldsymbol{H}(\theta)^{\mathrm{T}} \lambda
\end{aligned}
$$

ここで, $\boldsymbol{l}(\theta)=\left(\boldsymbol{\Phi}(\theta)^{-1}\right)^{\mathrm{T}} \boldsymbol{\lambda}$ の関係を用いた . $\boldsymbol{\lambda}$ は 6 次 元の定べクトルである.式 (17) から分かるように $\boldsymbol{P}$ は制 御入力 $\boldsymbol{u}$ の係数になっており, 重要なべクトルで primer vector ${ }^{7)}$ と呼ばれるものである.

ポントリャーギンの原理を用いれば，燃料最小誘導則は この $\boldsymbol{P}$ を用いて次のように導ける。

$$
\boldsymbol{u}(\theta)= \begin{cases}-\boldsymbol{P}(\theta) & |\boldsymbol{P}(\theta)|<1 \\ -\frac{\boldsymbol{P}(\theta)}{|\boldsymbol{P}(\theta)|} & |\boldsymbol{P}(\theta)|>1\end{cases}
$$

この制御則で重要なことは, 燃料最小となる制御入力 $u$ が primer vector $\boldsymbol{P}$ ，つまり式 (18)より 6 次元定ベクト ル $\lambda$ のみで一意に決定されることである .

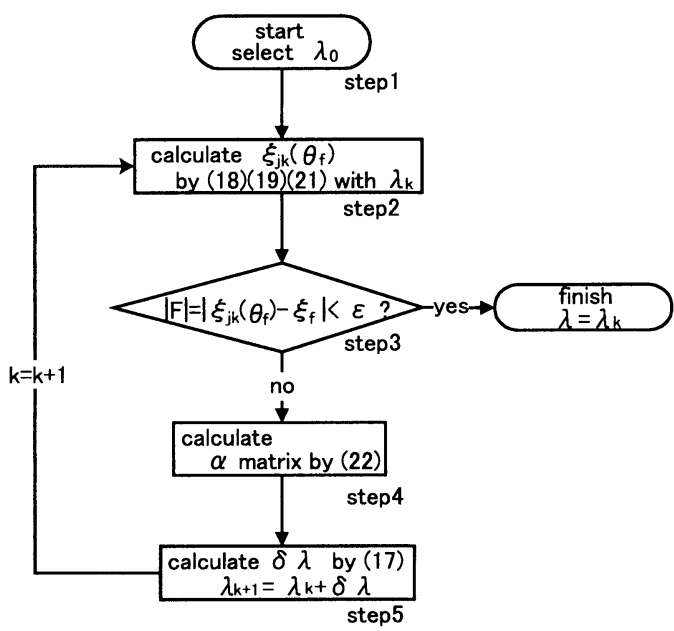

第 2 図 低推力燃料最小計算のアルゴリズム

3.3 低推力燃料最小計算アルゴリズム shooting method に基づいたオンボードにおける燃料最小計算のアルゴリ ズムを第 2 図に示す . 計算の簡便さの理由から , 次のよう な状態変数の変換を行っている.

$$
\boldsymbol{\xi}(\theta)=\boldsymbol{\Phi}^{-1}(\theta) \boldsymbol{y}(\theta)-\boldsymbol{\Phi}^{-1}\left(\theta_{0}\right) \boldsymbol{y}\left(\theta_{0}\right)
$$

このとき，推移行列による解 (12) は次のようになる .

$$
\boldsymbol{\xi}(\theta)=\int_{\theta_{0}}^{\theta} \beta(\tau) \boldsymbol{R}(\tau) \boldsymbol{u}(\tau) \mathrm{d} \tau
$$

\section{具体的には次のように行う.}

step $1 \lambda$ の初期推定值 $\boldsymbol{\lambda}_{0}$ を与える

step $2 \boldsymbol{\lambda}_{k}$ を用いて初期状態量 $\boldsymbol{\xi}_{k}\left(\theta_{0}\right)$ から燃料最小誘導

則 (19) 及び推移行列による解 (21) を用いて終端状態

量 $\boldsymbol{\xi}_{k}\left(\theta_{f}\right)$ を計算する

step $3 \boldsymbol{\xi}_{k}\left(\theta_{f}\right)$ と目標状態量 $\boldsymbol{\xi}_{f}$ との差 $\boldsymbol{F}=\boldsymbol{\xi}_{k}-\boldsymbol{\xi}_{f}$ を 計算し, 弚の絶対值が許容誤差 $(\epsilon)$ 以内であれば計算

を終了する. 弚うでなければ step 4 に進む step 4 次式により $\boldsymbol{\alpha}$ 行列を計算する

$$
\begin{aligned}
{[\alpha]_{a b} } & =\frac{\partial F_{a}}{\partial \lambda_{b}} \\
& \simeq \frac{F_{a}\left(\lambda_{1}, \cdots, \lambda_{b}+\Delta \lambda_{b}, \cdots\right)-F_{i}\left(\lambda_{1}, \cdots, \lambda_{b}, \cdots\right)}{\Delta \lambda_{b}}
\end{aligned}
$$

step 5 次式より $\boldsymbol{\lambda}$ の補正值 $\delta \boldsymbol{\lambda}$ を求め, $\boldsymbol{\lambda}_{k}$ に足して $k=k+1$ として step 2 に戻る

$$
\delta \boldsymbol{\lambda}=-\boldsymbol{\alpha}^{-1} \boldsymbol{F}
$$

4. フォーメーション全体の大域的低推力燃料最小誘導

4.1 フォーメーション中心座標系 前章で導いた低推力 燃料最小誘導は，境界条件が $\Sigma_{r}$ について与えられていた。 つまり境界時刻における位置と速度は，絶対座標で指定さ 


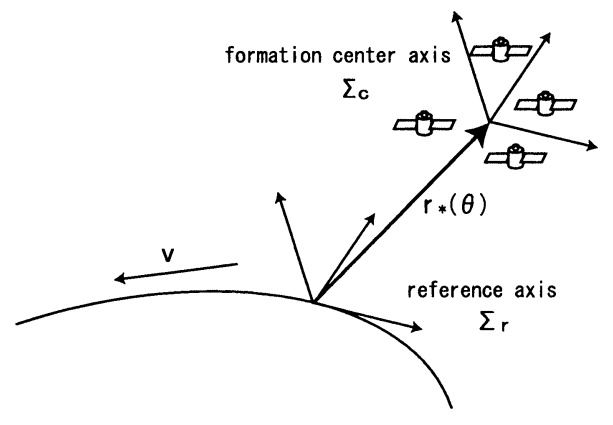

第 3 図 フォーメーション中心座標系

れていた .しかしフォーメーションフライトの場合 , フォー メーションの形，つまり各衛星間の相対位置のみが重要で あり，必ずしも光の絶対位置に制約を課す必要がないこと も多い，従って，全体の隊形の絶対位置を自由にすること で消費燃料を減らす余地がある.

乥こで, 第 3 図に示すように隊形変更時のフォーメーショ ンの重心位置を原点として $\Sigma_{r}$ に平行な座標系を考え， $\Sigma_{c}$ と置く. 前章における誘導則は, $\Sigma_{c}$ が $\Sigma_{r}$ に常に一致して いたと言える。

4.2 拘束条件及び評価関数 フォーメーションの形を指 定することは, フォーメーション内の $j$ 番目の衛星の $\Sigma_{c}$ に関する終端拘束条件を次のようにしたことに等しい．

$$
\boldsymbol{r}_{c}^{j}\left(\theta_{f}\right)=\boldsymbol{r}_{f}^{j}
$$

このとき，初期時刻においては $\Sigma_{r}$ と $\Sigma_{c}$ は一致している ので, 終端時刻におけるフォーメーション中心 $\left(\Sigma_{c}\right.$ の原 点) の $\Sigma_{r}$ に対する位置を $\boldsymbol{r}_{*}$ と置くと， $\Sigma_{r}$ に関する終端 拘束条件は次のようになる。

$$
\boldsymbol{r}_{r}^{j}\left(\theta_{f}\right)=\boldsymbol{r}_{f}^{j}+\boldsymbol{r}_{*}
$$

また，評価関数は次のようになる．

$$
J=\sum_{j=0}^{N} \int_{\theta_{0}}^{\theta_{f}} \frac{\boldsymbol{u}_{j}(\tau)^{\mathrm{T}} \boldsymbol{u}_{j}(\tau)}{s(\tau)^{2}} \mathrm{~d} \tau
$$

4.3 燃料最小誘導則 $j$ 番目の衛星に関するハミルトニ アンは, 前節の光れと同じように次のように求められる

$$
\begin{aligned}
H_{j}= & \boldsymbol{l}_{j}(\theta)^{\mathrm{T}} \boldsymbol{A}(\theta) \boldsymbol{y}_{j}(\theta) \\
& +\frac{1}{2 s(\theta)^{2}}\left[\boldsymbol{u}_{j}(\theta)^{\mathrm{T}} \boldsymbol{u}_{j}(\theta)\right. \\
& \left.+2 s(\theta)^{2} \beta(\theta) \boldsymbol{q}_{j}(\theta)^{\mathrm{T}} \boldsymbol{u}_{j}(\theta)\right]
\end{aligned}
$$

従って燃料最小誘導も前章と同じように次のように書ける。

$$
\boldsymbol{u}_{j}(\theta)= \begin{cases}-\boldsymbol{P}_{j}(\theta) & \left|\boldsymbol{P}_{j}(\theta)\right|<1 \\ -\frac{\boldsymbol{P}_{j}(\theta)}{\left|\boldsymbol{P}_{j}(\theta)\right|} & \left|\boldsymbol{P}_{j}(\theta)\right|>1\end{cases}
$$

ただし今考えるフォーメーション位置も自由度に入れた場 合は，絶対位置指定の場合と異なり，終端拘束条件が $(25)$

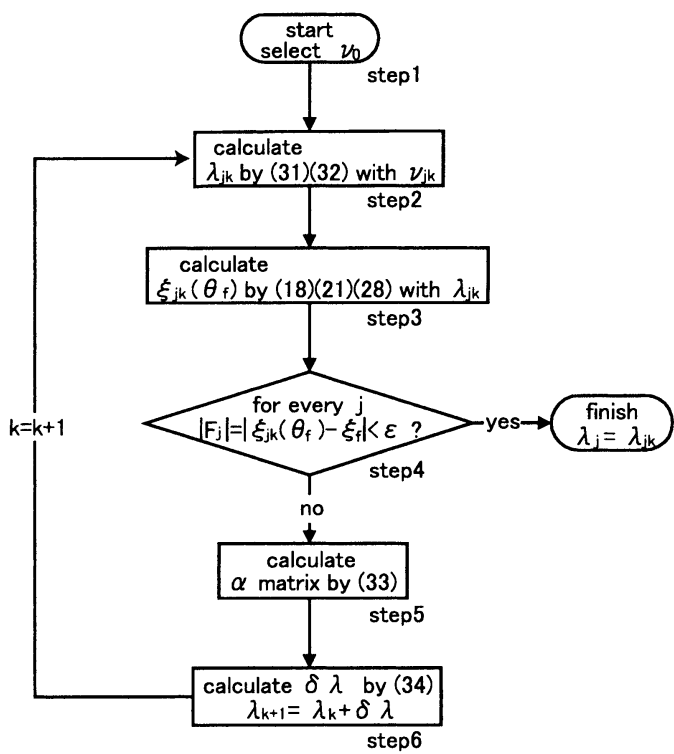

第 4 図 フォーメーション全体の燃料最小計算アルゴリズム

のようになるため, 変分法によれば次の随伴変数の終端条

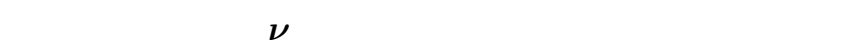
である .

$$
\begin{aligned}
& \boldsymbol{p}_{j}\left(\theta_{f}\right)=\boldsymbol{\nu}_{p j}+\frac{1}{N}\left(\boldsymbol{\nu}_{p 1}+\cdots+\boldsymbol{\nu}_{p N}\right) \\
& \boldsymbol{q}_{j}\left(\theta_{f}\right)=\boldsymbol{\nu}_{q j}
\end{aligned}
$$

$\lambda$ を用いて表せば次のようになる .

$$
\begin{aligned}
& \boldsymbol{H}\left(\theta_{f}\right)^{\mathrm{T}} \boldsymbol{\lambda}_{j}=\boldsymbol{\nu}_{p j}+\frac{1}{N}\left(\boldsymbol{\nu}_{p 1}+\cdots+\boldsymbol{\nu}_{p N}\right) \\
& \boldsymbol{G}\left(\theta_{f}\right)^{\mathrm{T}} \boldsymbol{\lambda}_{j}=\boldsymbol{\nu}_{q j}
\end{aligned}
$$

4.4 計算アルゴリズムフォーメーション全体の相対位 置指定誘導の燃料最小化アルゴリズムを第 4 図に示す .こ こでも, shooting method を用いており，具体的には次の ようになる。

step 1 すべての衛星 $(j)$ について $\nu_{j}$ の初期值 $\boldsymbol{\nu}_{j 0}$ を与 える

step $2 \quad \boldsymbol{\nu}_{j k}$ を用いて, (31) (32) 式から $\boldsymbol{\lambda}_{j k}$ を求める step $3 \boldsymbol{\lambda}_{j k}$ を用いて, 最小燃料誘導則 $(28)$ 及び推移行列 による解 $(21)$ から終端状態量 $\boldsymbol{\xi}_{j k}\left(\theta_{f}\right)$ を計算する step 4 すべての $j$ について , $\boldsymbol{\xi}_{j k}\left(\theta_{f}\right)$ と目標状態量 $\boldsymbol{\xi}_{j f}$ の差 $\boldsymbol{F}_{j}=\boldsymbol{\xi}_{j k}\left(\theta_{f}\right)-\boldsymbol{\xi}_{j f}$ を計算し, 光の絶対値か許 容誤差 $(\epsilon)$ 内であれば計算を終了する . 光うでなけれ ば step 5 に進む

step 5 次式により $\boldsymbol{\alpha}$ 行列を計算する

$$
\begin{aligned}
{[\alpha]_{a b} } & =\frac{\partial F_{a}}{\partial \nu_{b}} \\
& \simeq \frac{F_{a}\left(\nu_{1}, \cdots, \nu_{b}+\Delta \nu_{b}, \cdots\right)-F_{a}\left(\nu_{1}, \cdots, \nu_{b}, \cdots\right)}{\Delta \nu_{b}}
\end{aligned}
$$

ただし $, \boldsymbol{F}^{\mathrm{T}}=\left[\boldsymbol{F}_{1}^{\mathrm{T}}, \cdots, \boldsymbol{F}_{N}^{\mathrm{T}}\right], \boldsymbol{\nu}^{\mathrm{T}}=\left[\boldsymbol{\nu}_{1}^{\mathrm{T}}, \cdots, \boldsymbol{\nu}_{N}^{\mathrm{T}}\right]$ 
step 6 次式より $\boldsymbol{\nu}_{j k}$ の補正值 $\delta \boldsymbol{\nu}$ を求め, $\boldsymbol{\nu}_{j k}$ に足して $k=k+1$ として step 2 に戻る

$$
\delta \boldsymbol{\nu}=\boldsymbol{\alpha}^{-1} \boldsymbol{F}
$$

4.5 実用性から見た問題点 本節で求めた誘導則では， $\boldsymbol{\alpha}$ を求める際の積分計算の回数が衛星数の 2 乗に比例し， また収束も遅くオンボードでの計算には実用的ではない． というのは, 最適化計算時にフォーメーション全体の位置 をずらす度に燃料最小計算を行わなければならないために， 2 重の最適化計算を行う必要があるからである.

\section{5. 実用的なフォーメーション全体の大域的準燃料最小誘導}

5.1 問題点の対策 4.5 節における問題点に対して, 本 稿では目標時刻におけるフォーメーションの位置（つまり $\left.r^{*}\right)$ を求める際にインパルス近似を利用し, 乥して光の中 心位置に対する目標隊形への移行誘導には 3 章の低推力誘 導を行う準燃料最小誘導を提案する。

5.2 インパルス近似による最適なフォーメーション位 置 $1,8,9)$

5.2.1 インパルス近似 推力による加速度を $a$ とする時

$$
\Delta \boldsymbol{v}=\int_{t_{1}}^{t_{2}} \boldsymbol{a} \mathrm{d} t
$$

を一定に保ちつつ $t_{2} \rightarrow t_{1}, a \rightarrow \infty$ とした極限をインパ ルス近似と言う．つまり, 軌道変更が瞬間的に, かつ無限 の加速度によって行われるとした最適解である．

5.2.2 2 インパルス軌道 インパルス軌道を考えるにあ たり，r に関する速度べクトルを $\boldsymbol{v}$ とし，インパルスを加 える前後の量を光れ光れ $(\cdot)^{-},(\cdot)^{+}$と表すこととすると，

(12) 式より推移軌道においては次式が成り立つ .

$$
\left[\begin{array}{c}
\boldsymbol{r}_{f} \\
\boldsymbol{v}_{f}^{-}
\end{array}\right]=\boldsymbol{\Phi}\left(\theta_{f}\right) \boldsymbol{\Phi}\left(\theta_{0}\right)^{-1}\left[\begin{array}{l}
\boldsymbol{r}_{0} \\
\boldsymbol{v}_{0}^{+}
\end{array}\right]
$$

(36) において未知量 $\boldsymbol{v}_{f}^{-}, \boldsymbol{v}_{0}^{+}$について解くと次式を得る.

$$
\left[\begin{array}{c}
\boldsymbol{v}_{0}^{+} \\
\boldsymbol{v}_{f}^{-}
\end{array}\right]=\left[\boldsymbol{H}\left(\theta_{0}\right),-\boldsymbol{H}\left(\theta_{f}\right)\right]^{-1}\left[-\boldsymbol{G}\left(\theta_{0}\right), \boldsymbol{G}\left(\theta_{f}\right)\right]\left[\begin{array}{l}
\boldsymbol{r}_{0} \\
\boldsymbol{r}_{f}
\end{array}\right]
$$

従って，初期インパルス $\Delta \boldsymbol{v}_{0}$ および終端インパルス $\Delta \boldsymbol{v}_{f}$ は, 離心率 $e$, 初期時刻 $\theta_{0}$, 終端時刻 $\theta_{f}$, 乥して目標状態 量 $\boldsymbol{y}_{f}$ を指定すれば，(37) 及び次式により代数的に求める ことができる .

$$
\begin{aligned}
& \Delta \boldsymbol{v}_{0}=\boldsymbol{v}_{0}^{+}-\boldsymbol{v}_{0} \\
& \Delta \boldsymbol{v}_{f}=\boldsymbol{v}_{f}-\boldsymbol{v}_{f}^{-}
\end{aligned}
$$

5.2.3 フォーメーション全体の総 $\Delta v$ 最小化 インパル ス軌道においては, 燃料最小化問題の評価関数は総 $\Delta v$ と なる。

今 , 初期状態において $\Sigma_{c}$ と $\Sigma_{r}$ の原点が一致していると
すると， $\Sigma_{c}$ の $\Sigma_{r}$ に対する状態量 $\boldsymbol{y}^{*}(\theta)=\left[\boldsymbol{r}^{*}(\theta), \boldsymbol{v}^{*}(\theta)\right]$ について次式が成り立つ．

$$
\begin{aligned}
\boldsymbol{y}_{f}^{*-} & =\boldsymbol{\Phi}\left(\theta_{f}\right) \boldsymbol{\Phi}\left(\theta_{0}\right)^{-1} \boldsymbol{y}_{0}^{*+} \\
& =\boldsymbol{\Phi}\left(\theta_{f}\right) \boldsymbol{\Phi}\left(\theta_{0}\right)^{-1}\left[\begin{array}{c}
\mathbf{0} \\
\boldsymbol{v}_{0}^{*+}
\end{array}\right]
\end{aligned}
$$

従って，フォーメーションを構成する各衛星 $(j)$ の推移 軌道における $\Sigma_{r}$ での運動は次のように表せる .

$$
\boldsymbol{y}_{j f}^{-}+\boldsymbol{y}_{f}^{*-}=\boldsymbol{\Phi}\left(\theta_{f}\right) \boldsymbol{\Phi}\left(\theta_{0}\right)^{-1}\left(\boldsymbol{y}_{j 0}^{+}+\boldsymbol{y}_{0}^{*+}\right)
$$

よって, $j$ 番目の衛星が隊形変更に要する総 $\Delta \boldsymbol{v}$ は次の ようになる。

$$
\Delta \boldsymbol{v}_{j}=\left|\Delta \boldsymbol{v}_{j 0}+\boldsymbol{v}_{0}^{*+}\right|+\left|\Delta \boldsymbol{v}_{j f}+\boldsymbol{v}_{f}^{*+}-\boldsymbol{v}_{f}^{*-}\right|
$$

従って，フォーメーション全体の総 $\Delta \boldsymbol{v}$ は次のように なる .

$$
J=\sum_{j=1}^{N} \Delta \boldsymbol{v}_{j}=\sum_{j=1}^{N}\left|\Delta \boldsymbol{v}_{j 0}-\boldsymbol{c}_{0}\right|+\sum_{j=1}^{N}\left|\Delta \boldsymbol{v}_{j f}-\boldsymbol{c}_{f}\right|
$$

ここで， $c_{0}$ および $c_{f}$ は次のように定義している.

$$
\begin{aligned}
& \boldsymbol{c}_{f}=-\boldsymbol{v}_{f}^{*+}+\boldsymbol{v}_{f}^{+-} \\
& \boldsymbol{c}_{0}=-\boldsymbol{v}_{0}^{*+}
\end{aligned}
$$

つまり，インパルス仮定におけるフォーメーション全体 の燃料最小問題は (43) 式において $J$ を最小にするような $\boldsymbol{c}_{0}$ と $\boldsymbol{c}_{f}$ を求めることに帰着される . (44)，(45) 式からわ かるように， $c_{0}$ と $c_{f}$ は独立であるので別々に最小化すれ ばよい，従って，最適性の必要条件は以下のようになる .

$$
\begin{aligned}
& \left(\frac{\partial J}{\partial \boldsymbol{c}_{0}}\right)^{\mathrm{T}}=\sum_{j=1}^{N} \frac{-\left(\Delta \boldsymbol{v}_{j 0}-\boldsymbol{c}_{0}\right)}{\left|\Delta \boldsymbol{v}_{j 0}-\boldsymbol{c}_{0}\right|}=0 \\
& \left(\frac{\partial J}{\partial \boldsymbol{c}_{f}}\right)^{\mathrm{T}}=\sum_{j=1}^{N} \frac{-\left(\Delta \boldsymbol{v}_{j f}-\boldsymbol{c}_{f}\right)}{\left|\Delta \boldsymbol{v}_{j 0}-\boldsymbol{c}_{f}\right|}=0
\end{aligned}
$$

またこの方法では, 最適化計算の段階で全衛星のインパ ルスを噴く時間を一致させなければならないので, 事前に 全衛星で光の時間を申し合わせておきインパルスベクトル の情報を共有しておく必要がある .

5.3 燃料最小化アルゴリズムインパルス仮定をフォー メーション中心を求める際に利用する誘導則の計算は第 5 图のように行う.

5.2 節で述べた方法によりフォーメーションの中心位置 を求める際には, 共役勾配法を用いる. 乥してこの計算に より求めたフォーメーション中心に対する目標隊形への誘 導には, 拘束条件 $(25)$ を満たすように 3 章の低推力燃料最 小計算を行う.

具体的には次のように行う. 


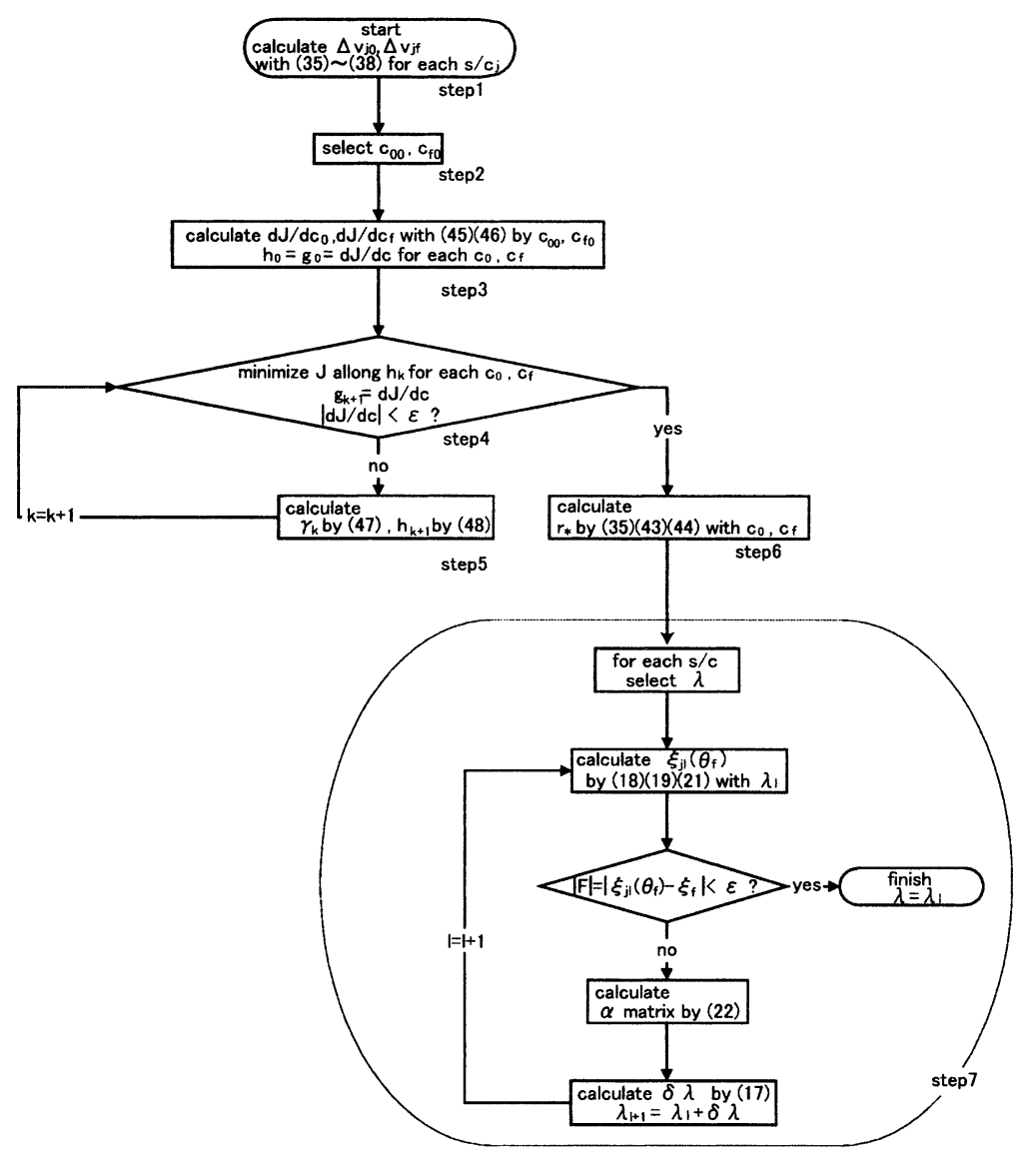

第 5 図 実用的なフォーメーション全体の準燃料最小化アルゴリズム

step 1 各衛星 $(j)$ について, 初期位置 $\left(\boldsymbol{r}_{0}\right)$ と終端位置 $\left(\boldsymbol{r}_{f}\right)$ から (36) (39) を用いて $\Delta \boldsymbol{v}_{j 0}, \Delta \boldsymbol{v}_{j f}$ を求める

step $2 \boldsymbol{c}_{0}$ および $\boldsymbol{c}_{f}$ の初期推量を仮定する $\left(\boldsymbol{c}_{00}, \boldsymbol{c}_{f 0}\right)$ step 3 (46)，(47) を用いて, 評価関数 $J$ の $\boldsymbol{c}_{0}$ と $\boldsymbol{c}_{f}$ に 関する勾配を光れ光れ求め， $\boldsymbol{g}_{0}, \boldsymbol{h}_{0}$ とする

step $4 \boldsymbol{c}_{0}$ と $\boldsymbol{c}_{f}$ 光れ光れについて, $\boldsymbol{h}_{j}$ の方向に評価関数

$J$ の最小探索を行い，最小となる $c_{0}$ と $c_{f}$ における

$J$ の勾配を $\boldsymbol{g}_{j+1}$ とする . この時, 勾配が 0 となった ら step 6 に進む $((46),(47))$.

step 5 (48) 式により $\gamma_{j}$ を求め，(49) 式により $\boldsymbol{h}_{j+1}$ を 求めて step 4 に戻る

$$
\begin{aligned}
& \gamma_{j}=\frac{\left(\boldsymbol{g}_{j+1}-\boldsymbol{g}_{j}\right) \cdot \boldsymbol{g}_{j+1}}{\boldsymbol{g}_{j} \cdot \boldsymbol{g}_{j}} \\
& \boldsymbol{h}_{j+1}=\boldsymbol{g}_{j+1}+\gamma_{j} \boldsymbol{h}_{j}
\end{aligned}
$$

step 6 (44) (45) から $\boldsymbol{v}_{f}^{*+}, \boldsymbol{v}_{f}^{*-}$ を求め, 光れをもとに終 端時刻におけるフォーメーションの中心位置 $\boldsymbol{r}_{f}^{*}$ を求 める

step 7 step 6 で求めた $\boldsymbol{r}_{f}^{*}$ を $\Sigma_{c}$ の原点として , (13)の ように $\Sigma_{r}$ における目標位置を定め, 3 章の衛星単機 の燃料最小化アルゴリズムを用いて $\lambda_{j}$ を計算する

\section{6. シミュレーション結果及び考察}

ここまでで, フォーメーションに対する 3 つの低推力誘 導のアルゴリズムを挙げた .すなわち，

\begin{tabular}{|c|c|c|}
\hline 参照軌道 & \multicolumn{2}{|c|}{$R_{p}=2 R_{e}, R_{a}=10 R_{e}(e=0.67)$} \\
\hline 初期時刻 & 0 & \\
\hline 終端時刻 & $1.2 \pi$ & \\
\hline 衛星数 & 4 & \\
\hline 最大推力 & $1[\mathrm{mN}]$ & \\
\hline 衛星重量 & $50[\mathrm{~kg}]$ & \\
\hline 初期状態量 & $\begin{aligned} \boldsymbol{r}_{1}^{\mathrm{T}} & =[0,0,0][\mathrm{m}] \\
\boldsymbol{r}_{2}{ }^{\mathrm{T}} & =[0,1000,0][\mathrm{m}] \\
\boldsymbol{r}_{3}{ }^{\mathrm{T}} & =[0,2000,0][\mathrm{m}] \\
\boldsymbol{r}_{4}{ }^{\mathrm{T}} & =[0,3000,0][\mathrm{m}]\end{aligned}$ & $\begin{aligned} \boldsymbol{v}_{1}^{\mathrm{T}} & =[0,0,0][\mathrm{m} / \mathrm{s}] \\
\boldsymbol{v}_{2}{ }^{\mathrm{T}} & =[0,0,0][\mathrm{m} / \mathrm{s}] \\
\boldsymbol{v}_{3}{ }^{\mathrm{T}} & =[0,0,0][\mathrm{m} / \mathrm{s}] \\
\boldsymbol{v}_{4}{ }^{\mathrm{T}} & =[0,0,0][\mathrm{m} / \mathrm{s}]\end{aligned}$ \\
\hline 目標状態量 & $\begin{aligned} \boldsymbol{r}_{1}^{\mathrm{T}} & =[2000,0,0][\mathrm{m}] \\
\boldsymbol{r}_{2}{ }^{\mathrm{T}} & =[0,2000,0][\mathrm{m}] \\
\boldsymbol{r}_{3}{ }^{\mathrm{T}} & =[-2000,0,0][\mathrm{m}] \\
\boldsymbol{r}_{4}{ }^{\mathrm{T}} & =[0,-2000,0][\mathrm{m}]\end{aligned}$ & $\begin{aligned} \boldsymbol{v}_{1}{ }^{\mathrm{T}} & =[0,0,0][\mathrm{m} / \mathrm{s}] \\
\boldsymbol{v}_{2}{ }^{\mathrm{T}} & =[0,0,0][\mathrm{m} / \mathrm{s}] \\
\boldsymbol{v}_{3}{ }^{\mathrm{T}} & =[0,0,0][\mathrm{m} / \mathrm{s}] \\
\boldsymbol{v}_{4}{ }^{\mathrm{T}} & =[0,0,0][\mathrm{m} / \mathrm{s}]\end{aligned}$ \\
\hline
\end{tabular}

第 1 表 シミュレーション計算条件

(1) 絶対位置を指定した誘導 (3 章) [30]

(2) フォーメーション位置を自由度にいれ，兴の位置をイ ンパルス近似によって求める誘導 (5 章) [31]

(3) フォーメーション位置を自由度に入れた, 完全燃料最 小誘導 (4 章) $[\simeq 600]$

燃料最小の度合いは (1) (2) (3) の順に大きくなる . 右に示 してある数字は (章) [pentium IV $2.4 \mathrm{GHz}$ での計算時間 (s)]である .これらのアルゴリズムを用いたシミュレーショ ン結果を第 6 ～ 8 図に示す. 弚の計算条件は第 1 表に示す. 各図の左側は各衛星の制御入力の大きさの推移, 右側は 

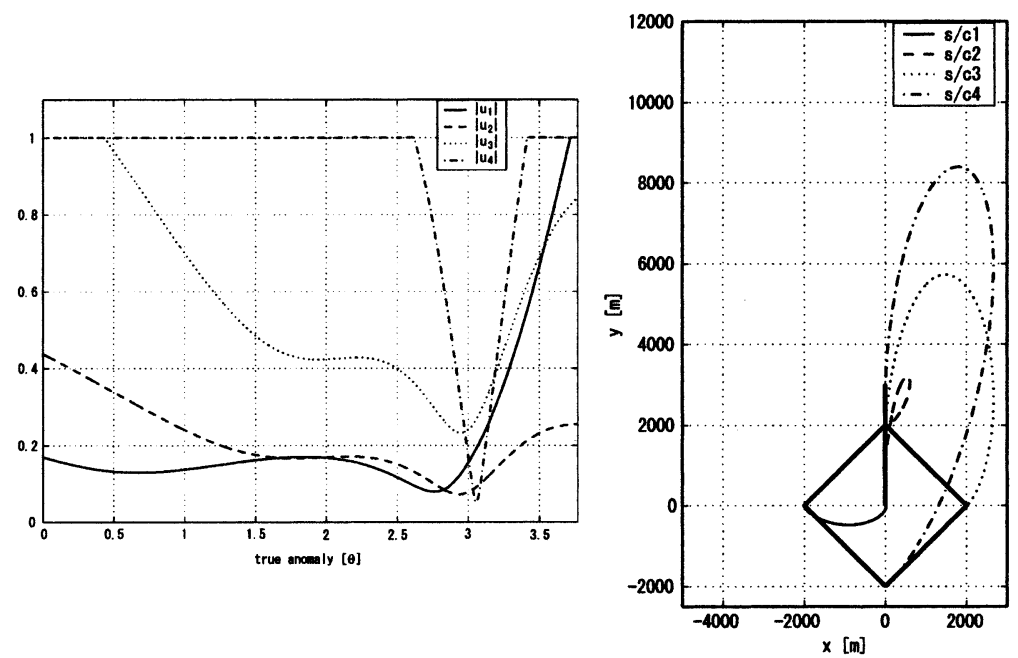

第 6 図 “絶対位置を指定した誘導”シミュレーション結果
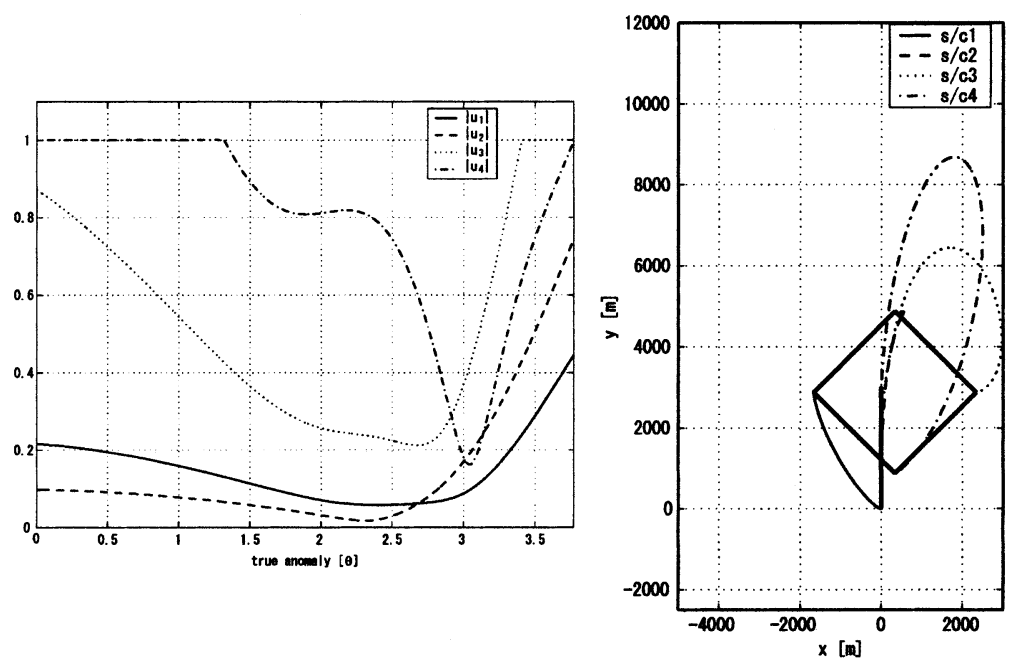

第7図 “フォーメーション位置を自由度に入れ，弚の位置をインパルス近似によって求める誘導”シミュレーション結果
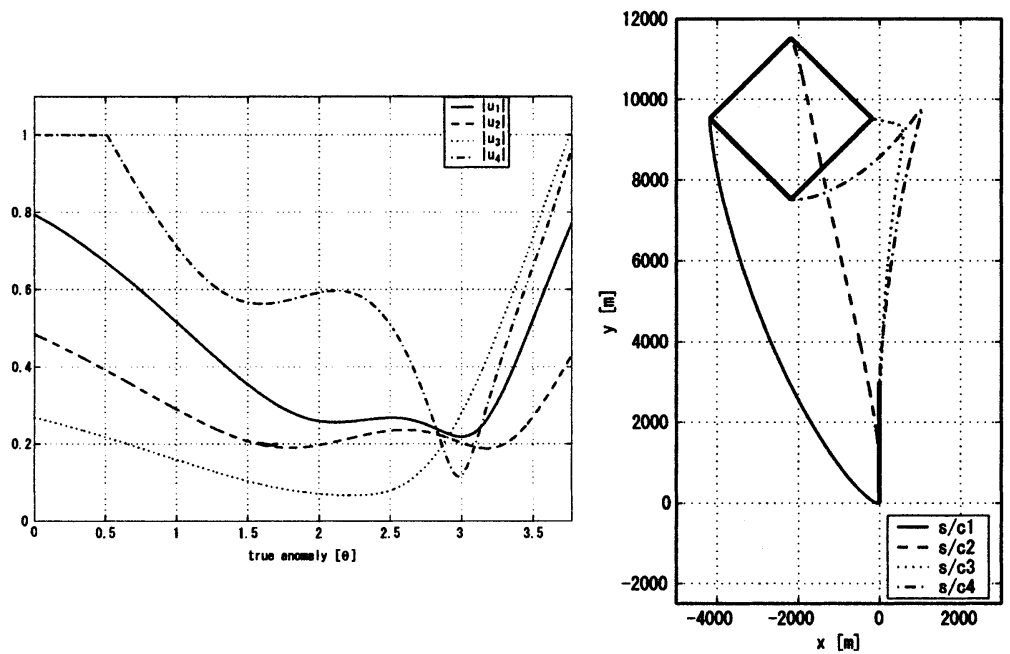

第 8 図 “フォーメーション位置を自由度に入れた , 完全燃料最小誘導”シミュレーション結果

$x y$ 平面における各衛星の軌道を表している.制御入力の大 きさを示す図から，第 6 図から第 8 図へと最適化の度合い
が大きくなるに従って各衛星の制御入力が平均化され，全 体として小さくなっていることが分かる .また ,フォーメー 


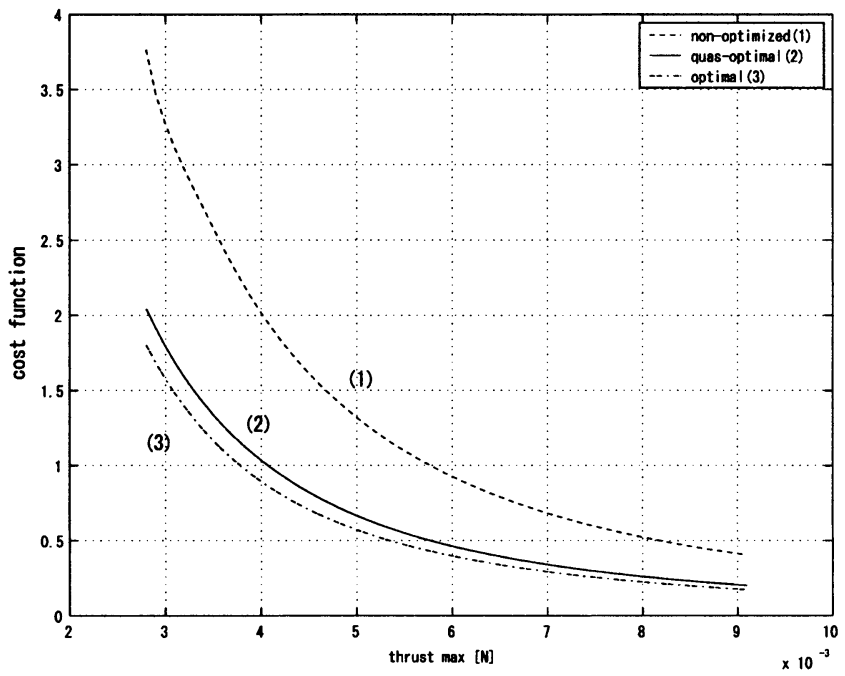

第 9 図 最大推力と各誘導の評価関数

\begin{tabular}{|c|c|c|}
\hline 参照軌道 & \multicolumn{2}{|c|}{$R_{p}=2 R_{e}, R_{a}=10 R_{e}(e=0.67)$} \\
\hline 初期時刻 & 0 & \\
\hline 終端時刻 & $1.2 \pi$ & \\
\hline 衛星数 & 4 & \\
\hline 最大推力 & $1[\mathrm{mN}]$ & \\
\hline 衛星重量 & $50[\mathrm{~kg}]$ & \\
\hline 初期状態量 & $\begin{aligned} \boldsymbol{r}_{1} \mathrm{~T} & =[0,0,0][\mathrm{m}] \\
\boldsymbol{r}_{2}{ }^{\mathrm{T}} & =[0,1000,0][\mathrm{m}] \\
\boldsymbol{r}_{3} \mathrm{~T} & =[0,2000,0][\mathrm{m}] \\
\boldsymbol{r}_{4}{ }^{\mathrm{T}} & =[0,3000,0][\mathrm{m}]\end{aligned}$ & $\begin{array}{l}\boldsymbol{v}_{1}^{\mathrm{T}}=[0,0,0][\mathrm{m} / \mathrm{s}] \\
\boldsymbol{v}_{2}^{\mathrm{T}}=[0,0,0][\mathrm{m} / \mathrm{s}] \\
\boldsymbol{v}_{3}{ }^{\mathrm{T}}=[0,0,0][\mathrm{m} / \mathrm{s}] \\
\boldsymbol{v}_{4}{ }^{\mathrm{T}}=[0,0,0][\mathrm{m} / \mathrm{s}]\end{array}$ \\
\hline 目標状態量 & $\begin{array}{l}\boldsymbol{r}_{1}^{\mathrm{T}}=[2000,0,0][\mathrm{m}] \\
\boldsymbol{r}_{2}{ }^{\mathrm{T}}=[0,2000,0][\mathrm{m}] \\
\boldsymbol{r}_{3}{ }^{\mathrm{T}}=[-2000,0,0][\mathrm{m}] \\
\boldsymbol{r}_{4}{ }^{\mathrm{T}}=[0,-2000,0][\mathrm{m}]\end{array}$ & $\begin{array}{l}\boldsymbol{v}_{1}^{\mathrm{T}}=[0,0,0][\mathrm{m} / \mathrm{s}] \\
\boldsymbol{v}_{2}{ }^{\mathrm{T}}=[0,0,0][\mathrm{m} / \mathrm{s}] \\
\boldsymbol{v}_{3}{ }^{\mathrm{T}}=[0,0,0][\mathrm{m} / \mathrm{s}] \\
\boldsymbol{v}_{4}{ }^{\mathrm{T}}=[0,0,0][\mathrm{m} / \mathrm{s}]\end{array}$ \\
\hline
\end{tabular}

ションの位置は最適化することで $-x, y$ 方向へ大きくず れていっている。

第 9 図は各場合の制御入力の全衛星の合計を最大推力に 対してプロットしたものである.最大推力以外の条件は第 2 表で与えた .この図から準燃料最適化アルゴリズムは, 完 全燃料最小誘導に非常に近く, 十分に実用上有効であるこ とが分かる. 最大推力が小さくなる程, 準最適解と完全最 適解の差が大きくなっているが, これはインパルス近似か ら離れていくことを考えると当然といえる．

\section{7. 誘導に必要な情報量・計算量の評価 ${ }^{1)}$}

フォーメーションフライトにおいては, 光の隊形変更時 などにおいて衝突を避けたりするために, 他の衛星の軌道 を知ってオンボードで自律的に処理されることか望まれる． 谷のためには, 衛星数か増えた場合にでも処理可能なよう な少ない情報量・計算量を共有するだけて誘導できること が必要である . 本稿で導いた制御則は, 次のようにこの点 でフォーメーションフライトの誘導に適しているといえる． 3 章において導いた誘導則は, 衛星の燃料最小軌道が下
の 14 個の值だけで表せた .

$b:$ 式 (11)

$\theta_{0}:$ 初期時刻

$\boldsymbol{y}_{0}:$ 初期状態量

$\lambda: 6$ 次元の定ベクトル

つまり始点から $\lambda$ のみで定まる制御入力によりフィード フォワード計算によるために，各時刻ごとに制御入力を与 える場合 (時間に比例) に比べ少ない情報量を共有するだ けでよくなり，オンボードでのリアルタイム計算を可能と する.また計算は, shooting method を用いて 2,3 回の 積分 iteration を含む最適化計算を行うのみでよい .

フォーメーション全体の大域的な燃料最適化においては， 4 章の最適化アルゴリズムを用いると最適化計算の中に最 適化計算を含み, 収束が悪く, 計算量も衛星数が増えるに つれ指数関数的に増大するが, 5 章の準最適化アルゴリズ ムを用いることで，最適性を大幅に犠牲にすることなく計 算量を大きく減らすことができる．

$$
\text { 8. 結論 }
$$

本稿では, フォーメーションフライトを構成する衛星数 が多数機になった場合に特に必要になってくると思われる， 情報量が少なく，オンボード計算可能な計算量となるよう な連続推力燃料最小化アルゴリズムについて議論してきた . フォーメーションの位置を自由度に入れた誘導では, 光の位 置をインパルス近似を用いて求めることで, 完全燃料最小 に極めて近い実用的な準燃料最小アルゴリズムを提案した .

\section{参 考 文 献}

1) 津田雄一: 情報管理と誘導則の関係を考慮した大規模衛星群フォー メーションフライトアーキテクチャに関する研究, 東京大学工学 系研究科学位論文, 2003.

2) How, J. P. and Inalhan, G.: Relative Dynamics and Control of Spacecraft Formations in Eccentric Orbits, AIAA Paper 2000-4443, 2000

3) Carter, T.: New Form for the Optimal Rendezvous Equations near a Keplerian Orbit, J. Guid., 13 (1990), pp. 183-186.

4) Carter, T.: Optimal Power-Limited Rendezvous of a Spacecraft with Bounded Thrust and General Linear Equations of Motion, J. Guid. Control Dynam., 87 (1995), pp. 487-515.

5) Carter, T. and Humi, M.: Fuel-Optimal Rendezvous near a Point in General Keplerian Orbit, J. Guid., 10 (1987), pp. 567-573.

6) Marec, J. P.: Optimal Space Trajectories, Elsevier Scientific Publishing Company, New York, 1979.

7) Lawden, D. F.: Optimal Trajectories for Space Navigation, Butterworths, London, 1963.

8) Tsuda, Y. and Nakasuka, S.: Impulsive Optimal Guidance Algorithm for Formation Flying Spacecraft, Proceedings of the 23rd International Symposium on Space Technology and Science, ISTS2002-d-51, 2002.

9) Tsuda, Y. and Nakasuka, S.: Optimal Guidance Law for Standby-Orbit Insertion for Formation Flying Spacecraft, Proceedings of the 12th ISAS Workshop on Astrodynamics and Flight Mechanics, A-4, 2002. 